\title{
Investigating the prevalence of resistance genes in Listeria monocytogenes isolated from food and clinical samples
}

\author{
Ali Shivaee ${ }^{1}$, Shahla Shahbazi ${ }^{2}$, Afsaneh Gholami ${ }^{3}$, Parham Kianoush pour ${ }^{4}$, Faramarz Masjedian Jazi ${ }^{5}$ \\ ${ }^{1}$ MSc in Medical Microbiology, Department of Microbiology, School of Medicine, Iran University of Medical Sciences, \\ Tehran, Iran \\ ${ }^{2}$ Ph.D Candidate, Department of Bacteriology, Pasteur Institute of Iran, Teheran, Iran \\ ${ }^{3}$ MSc in Microbiology, Department of Biology, Alborz Branch, Islamic Azad University, Karaj, Iran \\ ${ }^{4}$ Medical Microbiology Research Center, Qazvin University of Medical Science, Qazvin, Iran \\ ${ }^{5}$ Assistant Professor in Medical Microbiology, Department of Microbiology, School of Medicine, Iran University of
}

\begin{abstract}
Background: Listeriosis can be fatal for vulnerable groups of society. The disease has been widespread in recent years due to the large consumption of dairy and meat products. There is little information about the susceptibility of antibiotics and the pattern of Listeria monostigenesis gene resistance in Iranian society. Accordingly, the present study was conducted to investigate the antibiotic susceptibility and genetic resistance pattern of Listeria monosteogenesis strains isolated from different clinical and environmental sources.

Materials and methods: In this study, 55 isolates were tested for antibiotic susceptibility by disk diffusion in agar and genetic pattern by polymerase chain reaction (PCR).

Results: $91 \%$ and $83 \%$ of the strains were resistant to streptomycin and Trimethoprim/sulfamethoxazole respectively. The result of PCR of antibiotic resistance genes showed that the prevalence of ermA, ermB, strA, tetA, tetS and ermC genes in isolates of Listeria monocytogenes was $50.90 \%(28 / 55), 21.81 \%(12 / 55)$, $89.9 \%(49 / 55), 0 \%(0 / 55), 21.81 \%(12 / 55)$ and $0 \%(0 / 55)$, respectively.

Conclusion: Due to the presence of 1/2a and 1/2c serotypes in isolated isolates and the presence of marker virulence genes in these strains, these isolates have potential for biological risks and listeriosis disease. Existence of this genetic pattern and resistance pattern can be partly due to the use of antibiotics during the production of dairy products. Regarding results of this study, the manner and rate of using animal antibiotics can be managed.

Keywords: Listeriosis, Community vulnerability groups, Listeria monocytogenesis, Antibiotic resistance, $P C R$.

Cited as: Shivaee A, Shahbazi SH, Gholami A, Kianoush pour P, Masjedian Jazi F. Investigating the prevalence of resistance genes in Listeria monocytogenes in isolated from food and clinical samples. Medical Science Journal of Islamic Azad University, Tehran Medical Branch 2019; 29(4): 322-328.

Correspondence to: Faramarz Masjedian Jazi

Tel: +989123905926

E-mail: Fmasjedian@yahoo.com

ORCID ID: 0000-0002-0242-6000

Received: 9 Jan 2019; Accepted: 7 Apr 2019
\end{abstract}


مجله علوم يزشكى دانشگاه آزاد اسلامى

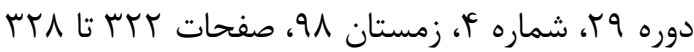

Original

Article

\section{بررسى شيوع زنهاى مقاومت در ليستريا مونوسيتوزنز جدا شده از نمونههاى}

\section{غذايى و بالينى}

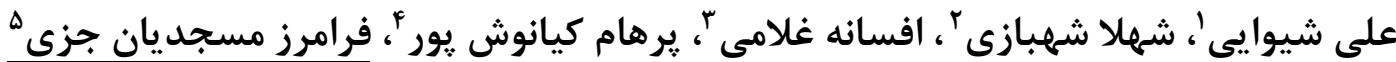

'كارشناسى ارشد ميكروب شناسى، دانشكده بزشكى دانشكاه علوم يزشكى ايران، تهران، ايران

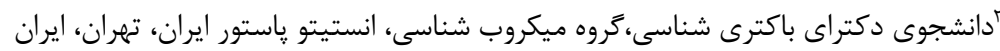

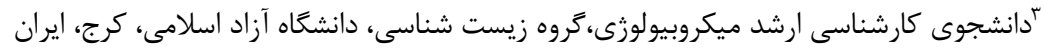

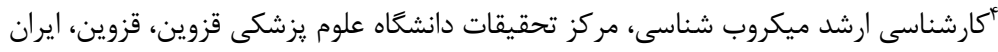

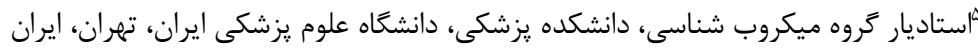

جكيده

سابقه و هدف: ليستريوزيس مىتواند براى كروههاى آسيب بذير جامعه كشنده باشد. /ين بيمارى در سالهاى اخير به دليل مصرف

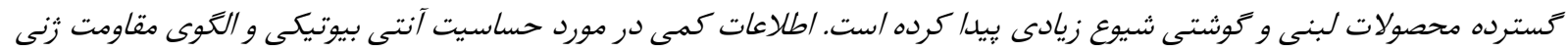

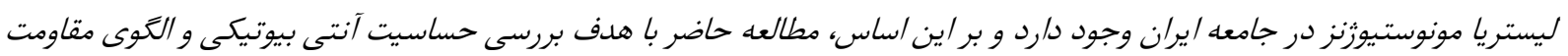

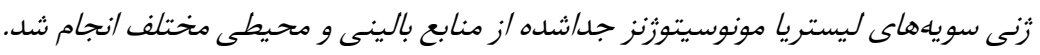

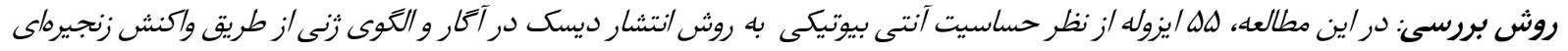

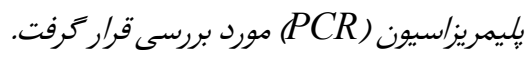

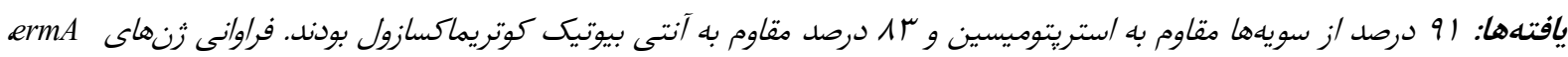
ermC g tetS detA ، strA armB بون

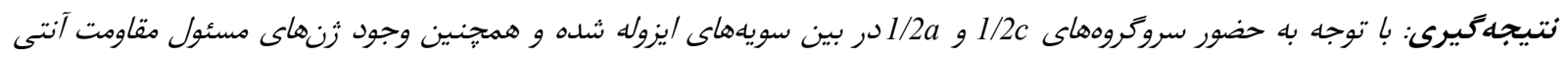

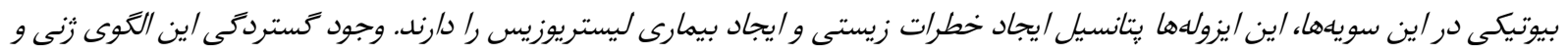

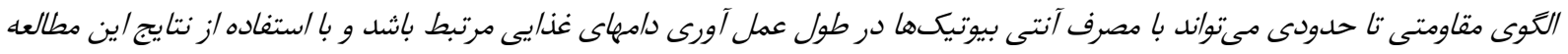

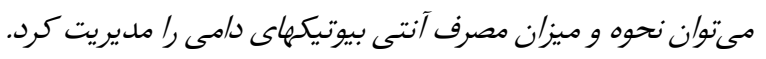

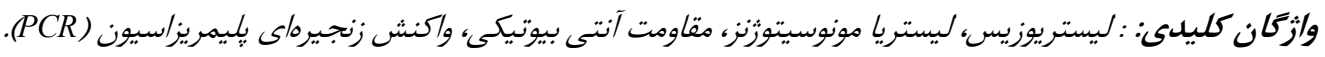

را مى توان از مدفوع حيوانات، خاك، فاضلاب، يوشش كياهى و

مقلهمه

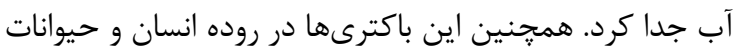
نيز حضور دارند (\{-1). در اين خانواده هشت كَونه باكترى

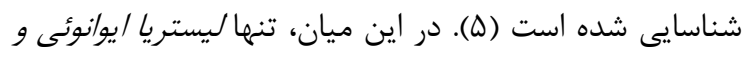
جنس ليستريا باكترىهاى گرم مثبت هوازى اختيارى هستند

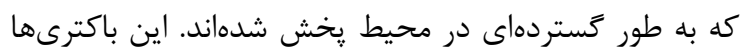

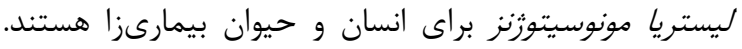

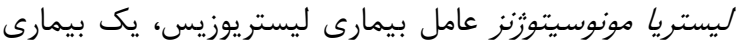

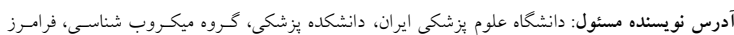

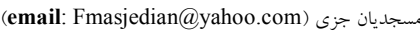
ORCID ID: 0000-0002-0242-6000

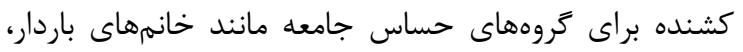

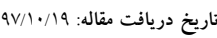


استفاده مىشود (91 (1)). به طور كلى حيوانات توليد كننده مواد غذايى حامل بسيارى از باكترىهاى ياتوزن و فرصت طلب

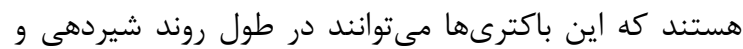

كشتار وارد محصولات گوشتى و لبنى شوند (IV). مكانيسمهاى زنتيكى دخيل در روند اين مقاومتها موضوعات جالب براى محققان و زيزشكان است. برخى مطالعات نشان مىدهند كه ليستريا مونوسيتوزنز مىتواند زنهاى مقاومت را از استريتوكوكها، استافيلوكوكها و انتروكوكها به دست مستونئ آورد (1), 9 (1). براساس مطالب عنوان شده هدف از انجام اين يروهش تعيين حساسيت ضد ميكروبى و الگوهاى زنى مقاومت ضد

ميكروبى در ليستريا مونوسيتوزنز جدا شده از منابع متنوع بود.

\section{مواد و روشها

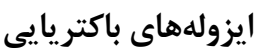
در اين مطالعه در مجموع Dه ايزوله (ايزوله غذايى: تعداد ها عدد،

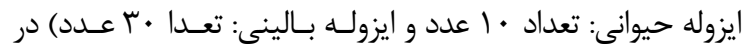

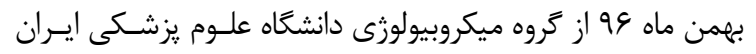

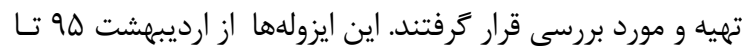
آبان 99 جمع آورى شده بودند.

غنى سازى، كشت،شناسايى مورفولوزيكى و بيو شيميايى

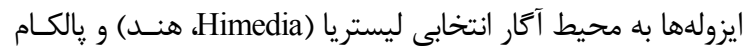

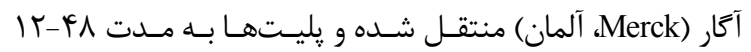

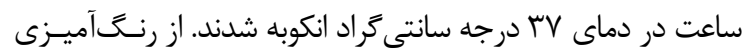

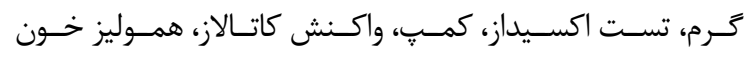
گَوسفندى در محيط آكار، MR-VP، تخمير قنـد (زايلـوز، رامنـوز،

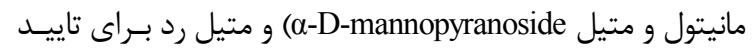
هويت سويههاى جدا شده استفاده شد.
اشخاص با ضعف سيستم ايمنى، افراد سالخورده و نوزادان

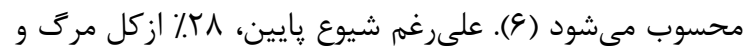

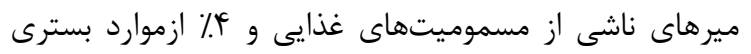
بيمارستانى با عفونتهاى ناشى از ليستريا مونوسيتوزنز در

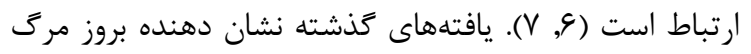

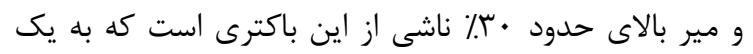

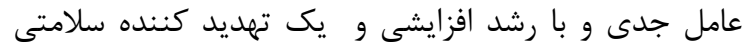
تبديل شده است. در دهلهاى حذشته، جندين مورد شيوع

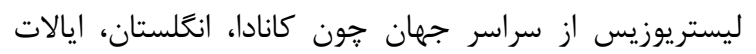
متحده آمريكا، فرانسه و ديخر كشورها گزارش شده است (^). راه انتقال اصلى ليستريا مونوسيتوزنز به انسان از طريق ناخالصى محيطى موجود در مواد غذايى آماده مصرف است

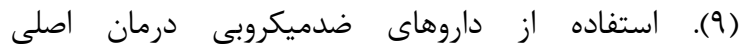
ليستريوزيس است. در حال حاضر تركيبى از آنتىبيوتيكهاى آمئي

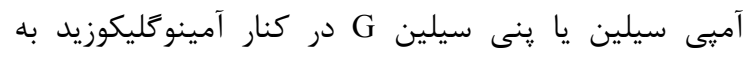
عنوان درمان ليستريوزيس توصيه ميىشود. به طوركلى، تمام

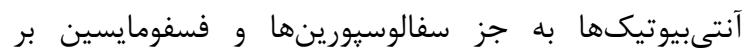

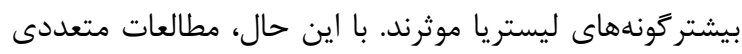

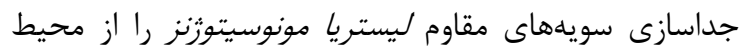

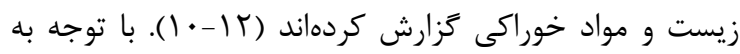
شيوع بالاى سويههاى مقاوم ليستريا مونوسيتوزنز به عوامل

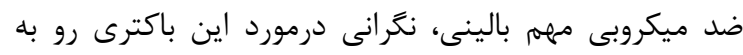

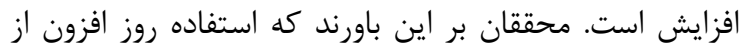

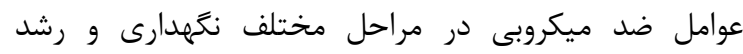
حيوانات دامى دليل اصلى افزايش شيوع سويههاى مقاوم به ميه

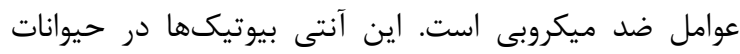

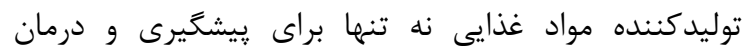
بيمارى، بلكه براى افزايش رشد و راندمان تغذيه حيوانات

جدول ا. يرايمرهاى مورد استفاده تشخيص زنهاى كد كننده مقاومت آنتى بيوتيكى در سويههاى ليستريا مونوسيتوزنز

\begin{tabular}{|c|c|c|}
\hline Specificity & primer sequence $\left(5^{\prime} \rightarrow 3^{\prime}\right)$ & Product size (bp) \\
\hline ermA & $\begin{array}{l}\text { F: TATCTTATCGTTGAGAAGGGATT } \\
\text { R: CTACACTTGGCTTAGGATGAAA }\end{array}$ & 139 \\
\hline ermB & $\begin{array}{l}\text { F: GAAAAGGTACTCAACCAAATA } \\
\text { R:AGTAACGGTACTTAAATTGTTTAC }\end{array}$ & 639 \\
\hline $\operatorname{str} A$ & $\begin{array}{l}\text { F: CTTGGTGATAACGGCAATTC } \\
\text { R: CCAATCGCAGATAGAAGGC }\end{array}$ & 572 \\
\hline tet $S$ & $\begin{array}{l}\text { F: TCCTTTGGGTAGTGGCATTC } \\
\text { R: AAGCATTCGGAAATCTGCTG }\end{array}$ & 420 \\
\hline tetA & $\begin{array}{l}\text { F: GGCCTCAATTTCCTGACG } \\
\text { R: AAGCAGGATGTAGCCTGTGC }\end{array}$ & 546 \\
\hline ermC & $\begin{array}{l}\text { F: CAAAACATAATATAGAT } \\
\text { R: CTAATATTGTTTAAATCGTCAAT }\end{array}$ & 641 \\
\hline
\end{tabular}




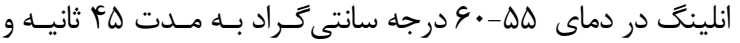

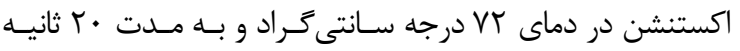
برنامه اجرايى واكنش زنجيرهاى يليمريزاسيون در اين مطالعه بود.

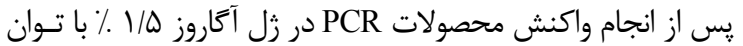

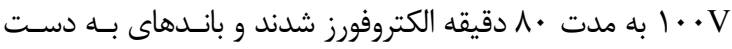
آمـده از طريـق سيسـتم PCR products Gel Documentation مورد ارزيابى قرار زرفتند. اندازه محصولات PCR در مقايسه با لـدر plus DNA ladder,Fermentas, Waltham, ) 1..bp بassachusetts, USA بهعنوان ماركر رفرنس اندازه DNA مـورد

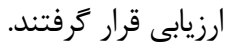

يافتهها يروفايل مقاومت آنتى بويتيكى

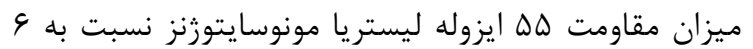

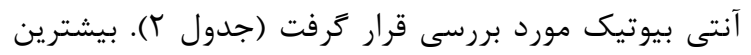
مقاومت (91 \% (1) نسبت به آنتى بيوتيك استريتوميسين

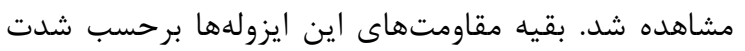
مقاومت از بيشترين به كمترين به ترتيب كوتريموكسازول

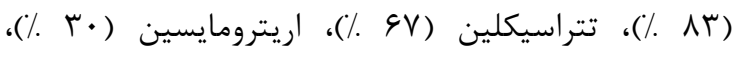

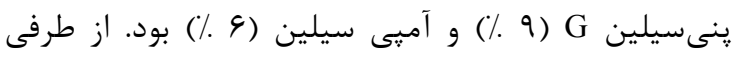
بيشترين حساسيت نسبت به آنتىبيوتيكهاى آميى سيلين

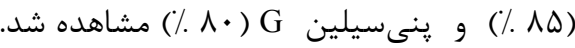

نتايج آزمايش زنجيره بِليمريزاسيون PCR بيشترين فراوانى زنهاى مورد بررسى در اين مطالعه مربوط به زن

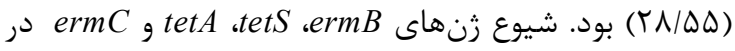
سويههاى ليستريا مونوسيتوزنز مورد مطالعه به ترنه ترتيب

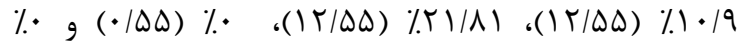

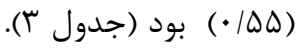

\section{تست حساسيت آنتى بيوتيكى}

به منظور انجام اين آزمايش از روش استاندارد Disk-diffusion (Kirby-Bauer 1966) كلنى از هر كشت خالص در r ميلى ليتر محيط مولرهينتون براث

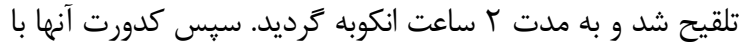
لوله ه/• مك فارلند مقايسه شد. براى بررسى مقاومت آنتى

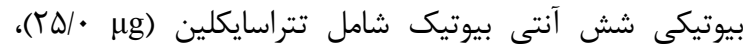

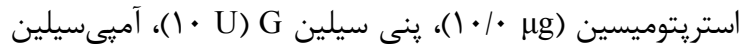

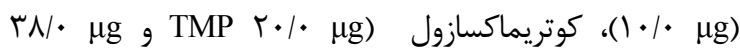

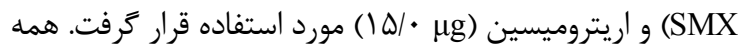
ديسكها از شركت Himedia هندوستان تهيه شده بود. ليستريا مونوسيتوزنز ATCC 7644 بهعنوان سويه استاندارد مورد استفاده

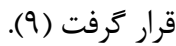

\section{شناسايى زنهاى مقاومت از طريق PCR}

ermA, ermB, استاندارد بامنظور تشخيص زنهاى PCR از روش و strA, tetS, tetA استخراج Roche Co, New York, USA) DNA) براى استخراج محتواى زنتيكى سويهها استفاده شد . كيفيت و كميت DNA

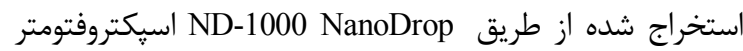
مورد (NanoDrop Technologies, Wilmington, DE, USA) بررسى قرار گرفت. توالى و اندازه يرايمرهاى طراحى شده براى تكثير در PCR در جدول I آمده است.

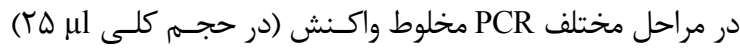

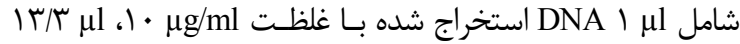

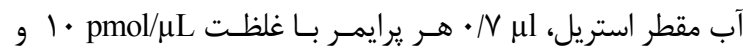

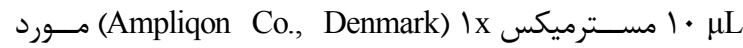
استفاده قرا گرفت.

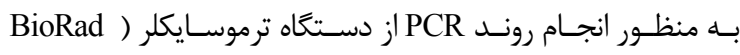
(Laboratories, Pittsburgh, PA

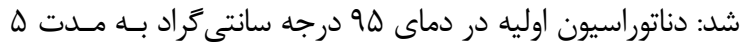

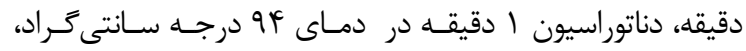

جدول r. نتايج حساسيت سويههاى ليستريامونوسيتوزنزبه روش انتشار ديسك در آكار

\begin{tabular}{|c|c|c|c|}
\hline حساس٪ & نيمه حساس. & مقاوم.\% & آنتى بيوتيك \\
\hline$\Delta$ & f & 91 & استر يتوميسين \\
\hline 11 & 9 & ^r & كوتريماكسازول \\
\hline ra & $\wedge$ & GV & تتراسيكلين \\
\hline 90 & $\Delta$ & r. & اريتروميسين \\
\hline$\wedge$. & 11 & 9 & ينىسيلين G \\
\hline$\Lambda \Delta$ & 9 & 4 & آميىسيلين \\
\hline
\end{tabular}


جدول سا. شيوع زنهاى ermC g ermA, ermB, strA, tetS, tetA در سويههاى ليستريامونوسيتوزنزمورد مطالعه.

\begin{tabular}{|c|c|c|c|c|c|}
\hline \multicolumn{6}{|c|}{ Genes } \\
\hline erm $\mathrm{A}$ & ermB & strA & tetS & tetA & ermC \\
\hline TA & IT & $4 q$ & IT & . & . \\
\hline$\% \Delta \cdot / 9$ & $\%$ YI/AI & $\% \wedge १ / ৭$ & $\% \quad r M / \Lambda$ & $\%$ & $\%$ \\
\hline
\end{tabular}

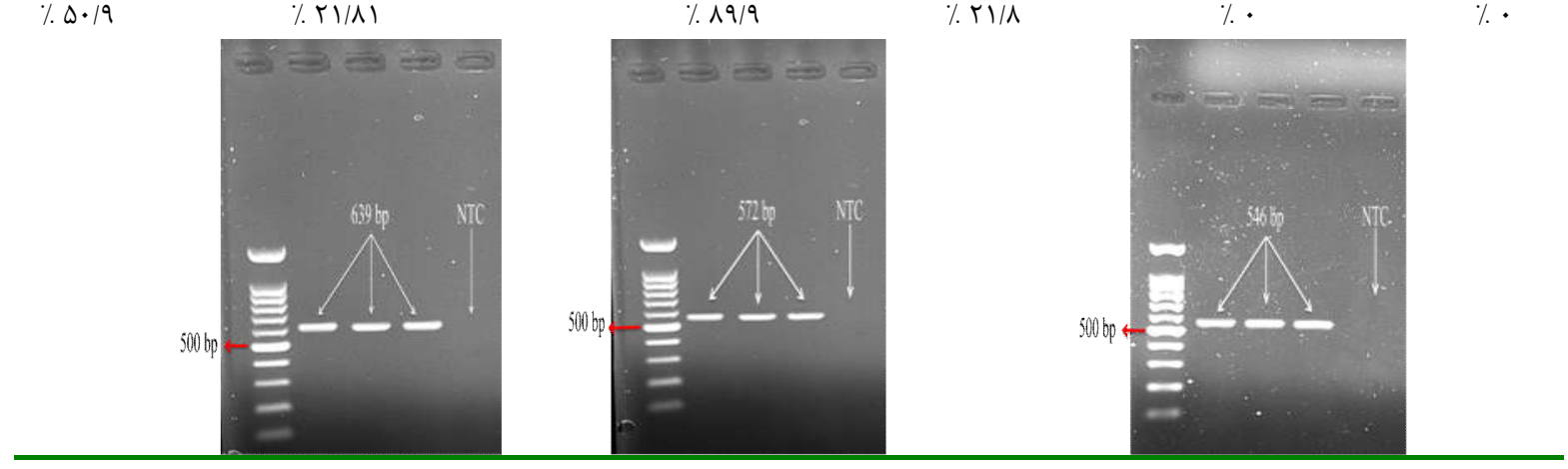

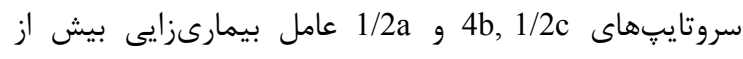

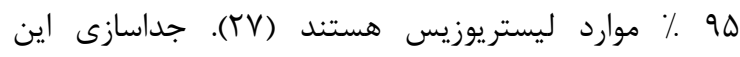

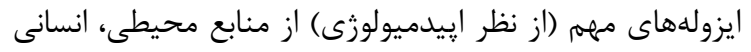

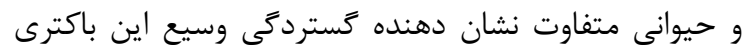
در محيط بِيرامون است. نتايج بررسىهاى مقاومت آنتى بيوتيكى در اين مطالعه نشان

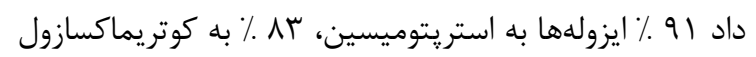

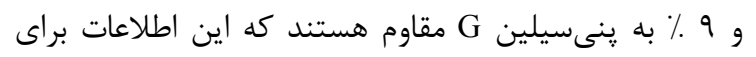

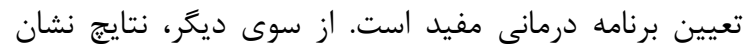

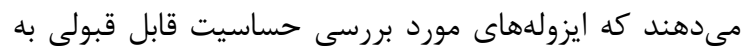

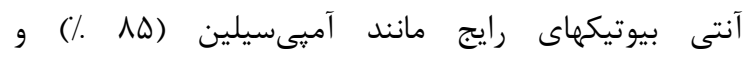

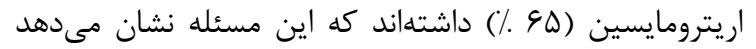

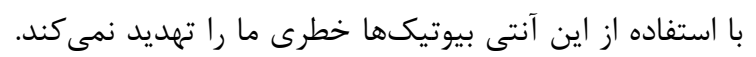
Charpentier

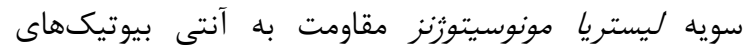

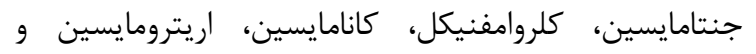

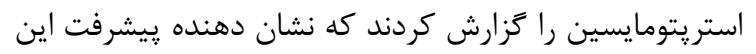

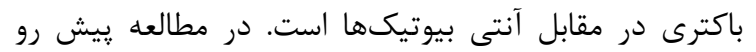

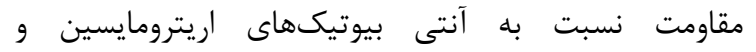

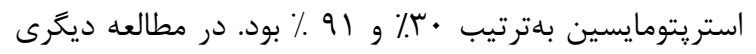

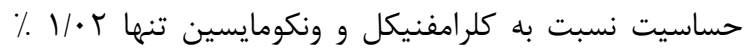

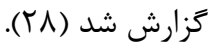
نتايج اين مطالعه نشان داد سويههاى جدا شدار شده از منابع

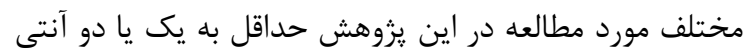
بيوتيك مقاوم هستند. همجنين، ايزولههاى مورد بررسى ائى

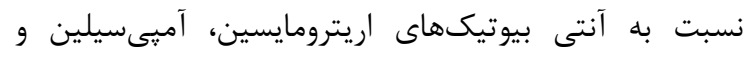

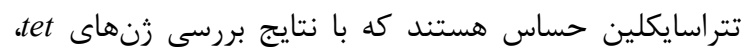
ليستريا منوسيتوزنز يك باكترى ياتوزن منتقله از مواد غذايى

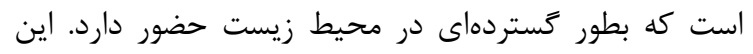

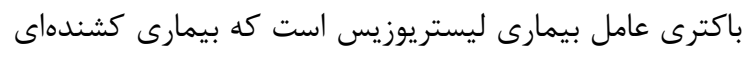

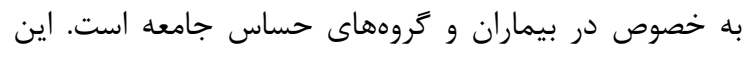

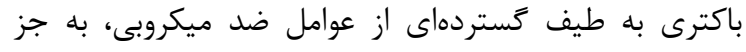

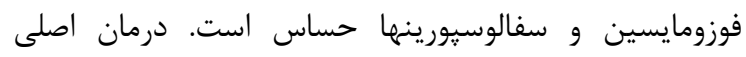

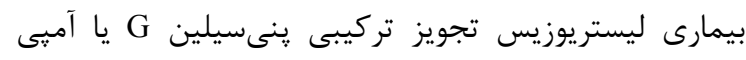

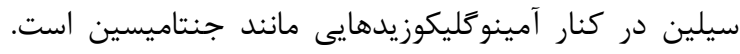

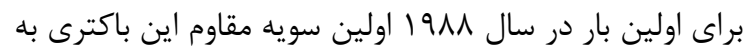

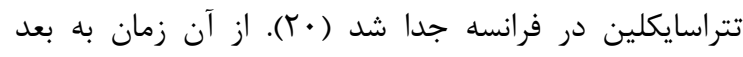

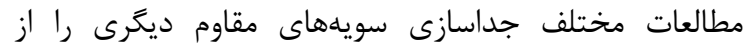

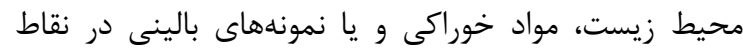

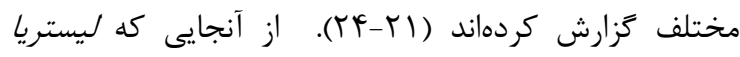

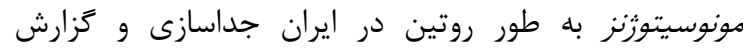

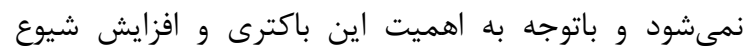

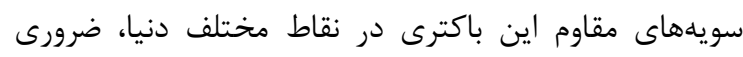

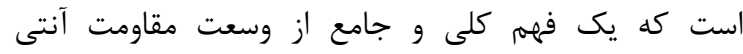

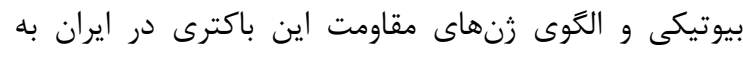

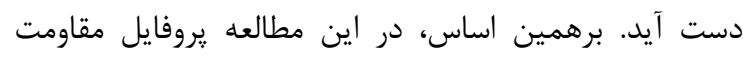

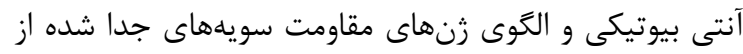

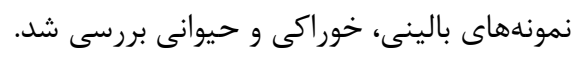

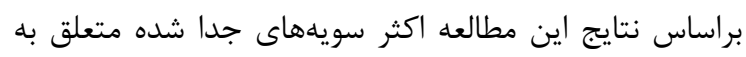

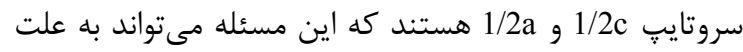

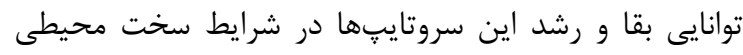

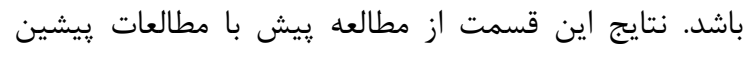

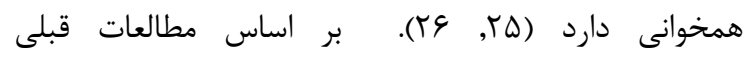




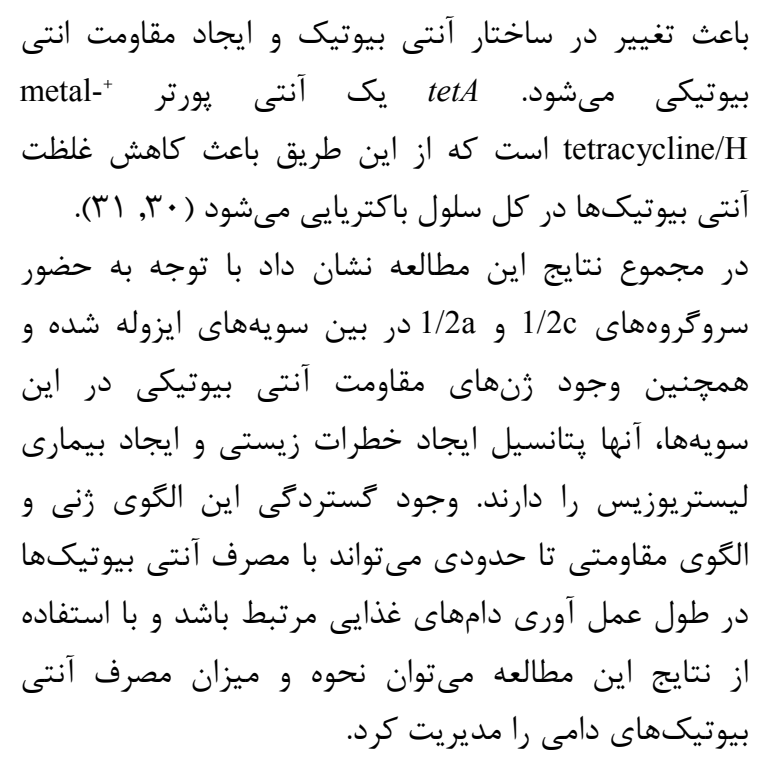

\section{REFERENCES}

1. Srinivasan V, Nam H, Nguyen L, Tamilselvam B, Murinda S, Oliver S. Prevalence of antimicrobial resistance genes in Listeria monocytogenes isolated from dairy farms. Foodborne Pathog Dis 2005;2:201-11.

2. Kalani BS, Pournajaf A, Sedighi M, Bahador A, Irajian G, Valian F. Genotypic characterization, invasion index and antimicrobial resistance pattern in Listeria monocytogenes strains isolated from clinical samples. Journal of Acute Disease 2015;4:141-6.

3. Behrooz SK, Lida L, Ali S, Mehdi M, Rasoul M, Elnaz O, et al. Study of MazEF, sam, and phd-doc putative toxinantitoxin systems in Staphylococcus epidermidis. Acta Microbiol Immunol Hung 2018;65:81-91.

4. Lotfollahi L, Nowrouzi J, Irajian G, Masjedian F, Kazemi B, Falahat LEA, et al. Prevalence and antimicrobial resistance profiles of Listeria monocytogenes in spontaneous abortions in humans. Afri J Microbiol Res 2011;5:1990-3.

5. Graves LM, Helsel LO, Steigerwalt AG, Morey RE, Daneshvar MI, Roof SE, et al. Listeria marthii sp. nov., isolated from the natural environment, Finger Lakes National Forest. I Int J Syst Evol Microbiol 2010;60:1280-8.

6. Farber J, Peterkin P. Listeria monocytogenes, a food-borne pathogen. Microbiol Rev 1991;55:476-511.

7. Mead PS, Slutsker L, Dietz V, McCaig LF, Bresee JS, Shapiro C, et al. Food-related illness and death in the United States. Emerg Infect Dis 1999;5:607.

8. Warriner K, Namvar A. What is the hysteria with Listeria? Trends in Food Science and Technology 2009;20:245-54.

9. Bahador A, SADEGHI KB, Valian F, Irajian G, Lotfollahi L. Phenotypic and genotypic characteristics of Listeria monocytogenes isolated from dairy and meat products. Avicenna J Clin Microb Infec 2015; 2: e26905.

10. Conter M, Paludi D, Zanardi E, Ghidini S, Vergara A, Ianieri A. Characterization of antimicrobial resistance of foodborne Listeria monocytogenes. Int J Food Microbiol 2009;128:497-500.

11. Chen J, Zhang X, Mei L, Jiang L, Fang W. Prevalence of Listeria in Chinese food products from 13 provinces between 2000 and 2007 and virulence characterization of Listeria monocytogenes isolates. Foodborne Pathog Dis 2009;6:7-14.

12. Morvan A, Moubareck C, Leclercq A, Hervé-Bazin M, Bremont S, Lecuit M, et al. Antimicrobial resistance of Listeria monocytogenes strains isolated from humans in France. Antimicrob Agents Chemother 2010;54:2728-31.

13. Yan H, Neogi SB, Mo Z, Guan W, Shen Z, Zhang S, et al. Prevalence and characterization of antimicrobial resistance of foodborne Listeria monocytogenes isolates in Hebei province of Northern China, 2005-2007. Int J Food Microbiol 2010;144:310-6.

14. Granier SA, Moubareck C, Colaneri C, Lemire A, Roussel S, Dao T-T, et al. Antimicrobial resistance of Listeria monocytogenes isolates from food and the environment in France over a 10-year period. Appl Environ Microbiol 2011; 77:2788-90.

15. Sakaridis I, Soultos N, Iossifidou E, Papa A, Ambrosiadis I, Koidis P. Prevalence and antimicrobial resistance of Listeria monocytogenes isolated in chicken slaughterhouses in Northern Greece. J Food Prot 2011;74:1017-21. 
16. Jamali H, Radmehr B, Meloni D. Prevalence of Listeria monocytogenes in poultry marketed in Iran: characterization and antimicrobial resistance of the isolates. Listeria monocytogenes: Incidence, growth behavior and control. 2015:105-16.

17. McEwen SA, Fedorka-Cray PJ. Antimicrobial use and resistance in animals. Clin Infect Dis 2002;34:S93-S106.

18. Charpentier E, Courvalin P. Antibiotic resistance in listeria spp. Antimicrob Agents Chemother 1999;43:2103-8.

19. Lungu B, O'Bryan CA, Muthaiyan A, Milillo SR, Johnson MG, Crandall PG, et al. Listeria monocytogenes: antibiotic resistance in food production. Foodborne Pathog Dis 2011;8:569-78.

20. Poyart-Salmeron C, Carlier C, Trieu-Cuot P, Courvalin P, Courtieu A. Transferable plasmid-mediated antibiotic resistance in Listeria monocytogenes. Lancet 1990;335:1422-6.

21. Facinelli B, Roberts M, Giovanetti E, Casolari C, Fabio U, Varaldo P. Genetic basis of tetracycline resistance in food-borne isolates of Listeria innocua. Appl Environ Microbiol 1993;59:614-6.

22. Hadorn K, Hächler H, Schaffner A, Kayser F. Genetic characterization of plasmid-encoded multiple antibiotic resistance in a strain of Listeria monocytogenes causing endocarditis. Eur J Clin Microbiol Infect Dis 1993;12:928-37.

23. Abuin CF, Fernández EQ, Sampayo CF, Otero JR, Rodriguez LD, Sáez AC. Susceptibilities of Listeria species isolated from food to nine antimicrobial agents. Antimicrob Agents Chemother 1994;38:1655-7.

24. Charpentier E, Gerbaud G, Jacquet C, Rocourt J, Courvalin P. Incidence of antibiotic resistance in Listeria species. J Infect Dis 1995;172:277-81.

25. Zhang Y, Yeh E, Hall G, Cripe J, Bhagwat AA, Meng J. Characterization of Listeria monocytogenes isolated from retail foods. Int J Food Microbiol 2007;113:47-53.

26. Yu T, Jiang X. Prevalence and characterization of Listeria monocytogenes isolated from retail food in Henan, China. Food Control 2014;37:228-31.

27. Fugett EB, Schoonmaker-Bopp D, Dumas NB, Corby J, Wiedmann M. Pulsed-field gel electrophoresis (PFGE) analysis of temporally matched Listeria monocytogenes isolates from human clinical cases, foods, ruminant farms, and urban and natural environments reveals source-associated as well as widely distributed PFGE types. J Clin Microbiol $2007 ; 45865-73$

28. Walsh D, Duffy G, Sheridan J, Blair I, McDowell D. Antibiotic resistance among Listeria, including Listeria onocytogenes, in retail foods. J Appl Microbiol 2001;90:517-22.

29. Zhang Y. Antimicrobial resistance of Listeria monocytogenes and Enterococcus faecium from food and animal sources [PhD Dissertation]. Maryland: University of Maryland; 2005.

30. Yamaguchi A, Someya Y, Sawai T. Metal-tetracycline/H+ antiporter of Escherichia coli encoded by transposon Tn10. The role of a conserved sequence motif, GXXXXRXGRR, in a putative cytoplasmic loop between helices 2 and 3. J Biol Chem 1992;267:19155-62.

31.Ginn SL, Brown MH, Skurray RA. Membrane topology of the metal-tetracycline/H+ antiporter TetA (K) from Staphylococcus aureus. J Bacteriol 1997;179:3786-9. 